\title{
Surgical residency training in the mission setting: current status and future directions
}

\author{
James D Smitha, Dan Poenaru', David Thompson ${ }^{\mathrm{c}}$, J Dwight Phillips ${ }^{\mathrm{d}}$ \\ ${ }^{a}$ MD. Professor Emeritus, Oregon Health and Science University, Oregon, United States \\ ${ }^{b}$ MD, MHPE, FRCSC,FACS, FCS(ECSA), Professor of Surgery and Pediatrics, Children's Hospital, Quebec, Canada \\ ${ }^{c}$ MD. Program Director, Pan African Academy of Christian Surgeons, Harpur Hospital, Egypt \\ ${ }^{d}$ MD, Professor of Pediatrics, Department of Pediatric and Adolescent Medicine, Mayo Clinic, Rochester, \\ Minnesota, United States
}

\section{Introduction}

Overseas professional education represents an expanding frontier of medical missions. In November 2015, 67 medical missionaries and academicians met in conjunction with the Global Missions Health Conference (GMHC) in Louisville, Kentucky. Most of the participants involved in the discussion were of North American origin, some originated and resided in other continents, and most participants had spent years working professionally outside of North America. They reviewed the current situation of international medical education missions and discussed future directions. A subgroup of 11 surgeon educators held specific discussions about surgery residency training and then reviewed their findings with the entire group. Additional discussions have been held since the November 2015 meeting. Arising from those discussions, this paper represents a consensus about the current state of international surgical training as medical missions and proposes steps to take towards ensuring ongoing best practices.

\section{Current Status of Surgical Training in Low- and Middle-Income Countries} (LMICs)

Medical care in Africa has rapidly evolved in the past 50 years. In the colonial era, a large part of modern medical care delivered in rural areas was by mission hospitals where they competed with traditional healers and some government outpatient clinics and district hospitals. Much of the surgical care in mission hospitals was provided by expatriate general practitioners who learned on the job by propping up a surgical textbook with a step-by-step description of the surgical procedure they were attempting to perform. There were very few national surgeons or, in some countries, even medical doctors. To fill this gap, the colonial medical systems in some countries trained medical officers (similar to our physicians assistants) to be specialists and some to do what is now called essential surgery. Despite this, there was and is a huge unmet need for curative and emergency surgical procedures in LMICs, especially in SubSaharan Africa.

Traditional surgical training in resourcelimited countries was limited for most of the $20^{\text {th }}$ century to the major universities, in the form of a 3year Masters in Medicine (MMed) program. This system typically generated less than a handful of surgeons each year in each country, thus perpetuating the dire surgical workforce shortage. In recent decades, however, the formation and expansion of the West African College of Surgeons (WACS) and, later, the College of Surgeons of East, Central, and Southern Africa (COSECSA) have successfully resulted in a major scale-up in yearly output of surgeons across Africa. ${ }^{1,2}$

Nov 2016. Christian Journal for Global Health, 3(2): 160-167. 
In the 1990s and 2000s, there was an international emphasis on the treatment of medical problems such as HIV and malaria. Surgery was felt to be an expensive luxury, and there was a lack of trained surgeons, but in recent years, surgery has become increasingly recognized as a primary care priority. In fact, 2015 was dubbed "the year of global surgery," with the World Health Assembly resolution WHA68.15 on essential surgical care and anesthesia, the $3^{\text {rd }}$ editions of the Disease Control Priorities (DCP-3), the Amsterdam Declaration on Essential Surgical Care, and, above all, the Lancet Commission on Global Surgery 2030. ${ }^{3-6}$ These efforts have resulted in an unprecedented enthusiasm and interest in global surgery as a distinct academic and clinical specialty that "places a priority on improving health and achieving equity in health for all people worldwide." ${ }^{, 7}$ Thus, what missionary surgeons and physicians had faithfully done for centuries without much recognition suddenly became fashionable and desirable.

With the interest in global surgery, there also came an unprecedented collaborative effort to train surgeons and other surgical care providers, primarily through North-South and South-South partnerships in the African surgical colleges mentioned earlier.

In the last 20 years, mission hospitals have recognized the need to train national physicians in family medicine and surgery to not only help fill this need, but also for their own sustainability. One such program is the Pan African Academy of Christian Surgeons (PAACS) that started as the vision of Dr. David Thompson, a general surgeon in a small mission hospital in southern Gabon. He realized that if he identified a Gabonese physician to come to the US for surgical training there was less than a $10 \%$ chance that the doctor would return to Gabon and even less of a chance he would be willing to work in his small rural hospital. His vision was to train national doctors in mission hospitals through a rigorous surgical training program based on a four-year, American-style, training program. After the first graduate had completed his training, the program was expanded to five years to meet the requirements for regional certification. ${ }^{8}$ The program now involves ten mission hospitals in eight countries, has graduated 52 surgeons and currently has 69 residents in training. The program is well on its way to exceed one of its early goals to train 100 surgeons by 2020 .

Another program is starting in Egypt to train ophthalmologists, with the plan to expand this to other residency training programs in the future. A few years ago, Dr. Nabil Jabbour, an ophthalmologist, recognized that many Egyptian residents who completed training received a local Master's of Medicine (MMed) specialty certificate to practice the specialty, but had limited hands-on surgical experience. From this, he had a vision to provide these individuals hands-on, up-to-date, clinical experience using visiting expatriate faculty in mission hospitals. Although this has had some success, it has been recognized that concentrating this training in a well-equipped hospital would provide better training with higher standards than scattered ad hoc training. From this came plans to build a hospital to serve as a base to upgrade the skills of ophthalmologists and expand this to include other specialties including Family Medicine.

Hospital Baptiste Biblique in Togo plans to start a PAACS surgical program in 2019, but is going to start by taking national interns. As a preliminary program to start a climate of education and training in the hospital, they plan to train these interns in some of the WHO designated essential surgical procedures.

A former resident, who completed the PAACS training program, has returned to his home country, the Democratic Republic of Congo, to work in a mission hospital. As he became overwhelmed with surgical patients, he used his training to train nurses or medical officers to do basic surgical procedures, thus, multiplying his hands as well as freeing him up to do more complicated procedures.

Nov 2016. Christian Journal for Global Health, 3(2): 160-167. 


\section{Recommendations for starting a}

\section{surgical residency in the mission setting}

The surgical training workshop at GMHC discussed surgical training in the mission setting. The following recommendations for starting a surgical training program were made based on the PAACS and personal experiences.

1. To start a surgical program using expatriate faculty, there should be a minimum of two, preferably three, full-time surgeons committed to the program for 3-5 years. At least one will need to be willing to take the responsibility of being program director.

2. The hospital needs to be committed to providing 24-hour anesthesiology services and preferably an on-site pathologist.

3. There must be a formal mission statement outlining the purpose and goal of training.

4. There should be clear guidelines regarding:

- who will be trained,

- what the trainee is expected to do on graduation,

- a contract as to how the graduate will repay their training such as work at a mission hospital, stay in the training hospital, return to their own country, etc,

- a formal interview of prospective residents and due diligence taken to review their prior medical training (medical school), post-medical school experience and an evaluation of their character and spiritual life,

- a plan of education for the entire five-year program that would include the surgical and spiritual curriculum and rotations for each year,

- adequate operating rooms that are well equipped to do the planned surgeries and adequate clinic areas,

- provision of adequate housing for faculty, residents, and visiting short term trainers.

5. There must be a plan for providing the trainees an option to obtain credentialing. In most countries this is becoming an important issue as a country's medical system matures.

6. There must be adequate funding reserves to build housing for faculty and residents and invest in essential medical infrastructure. Depending on the country and costs, some estimate this to require at least $\$ 300-500,000$ in reserves.

7. The program must have political support, including the medical establishment locally and at some point nationally. This may include support from the Ministry of Health (MOH) that may be active (financial support) or passive (good will) and recognition of the training program. In some countries, recognition may also involve the Ministry of Education (MOE) that may control recognition of training programs in some countries.

\section{Educational recommendations for a}

\section{training program}

1. The purpose of the program should not be to recreate the US training model, but rather adapt it to universally accepted standards of any program. These standards are available at little or no cost and should be adaptable to any training situation. ${ }^{9}$

2. There should be both a surgical and spiritual curriculum with written goals and objectives.

3. The program director is responsible to establish a learning environment of inquiry using:

- Conferences,

- Bedside teaching rounds,

- Journal club,

- Mortality and Morbidity (M\&M) conference,

- Didactic lectures,

- Clinical teaching,

- Regular formative and summative feedback,

- Participation by the resident in giving lectures, case presentations etc.,

- Involvement in the spiritual training program.

4. There should be formal evaluations of the program by faculty and residents which must be culturally sensitive.

Nov 2016. Christian Journal for Global Health, 3(2): 160-167. 
- Residents to receive regular formal feedback and should be informed how frequently this will occur and what to expect.

- Residents should give anonymous evaluation of faculty (this may be difficult to do in small programs and may require outsiders to receive this evaluation).

5. There should be a plan for regular spiritual training.

- The program should be evaluated by residents and faculty.

- The faculty need to model, encourage, and expect a Christian attitude in the residents' relationships with their patients, peers, colleagues, and all hospital personnel.

- The residents should be encouraged to work with the hospital chaplain if one is available.

6. There should be regular, scheduled in-service type assessments.

7. There should be a plan for faculty development programs for faculty and residents to train the teachers how to teach. The faculty should be role models for the residents to see that teaching and training are an intimate part of being a good doctor. $^{10}$

\section{Potential problems for surgical training program recognition and certification}

One of the problems PAACS recognized early on was the need to have recognition and approval of their specialty training programs by the national $\mathrm{MOH}$. The days of having training and being a good surgeon without some type of certification were rapidly disappearing as they have in the US. Also, to be a program attractive to potential residents, eligibility for some type of certification needed to be possible at the completion of training. When PAACS first started, it was recognized that there was a need for some credentialing organization to approve the training program. Loma Linda University was approached by a representative from PAACS, and they agreed to inspect, review, and approve the training programs if the programs met their standards. This was a first step.

It rapidly became apparent that to gain the MOH's approval, the programs would also need to have recognition and certification by an African organization as well. Most Sub-Saharan African surgical training programs are based in universities and university hospitals. The specialty certification is based on a university-conferred academic degree, a Master's of Medicine (MMed). $\mathrm{MOH}$ will then recognize the successful candidate as a specialist and will list them on the "Register of Specialists." An individual's paygrade and status will be recognized by this degree. During the training period, the resident must pay tuition to the university and at the end of training will be required to take a series of examinations. This made it difficult for non-university hospitals to have training programs.

In East Africa, the College of Surgeons of East, Central, and Southern Africa (COSECSA) started to bring surgeons together similar to the American College of Surgeon (ACS) or the UK Royal College of Surgeons (RCS). One of the goals was to provide certification for specialists similar to what the RCS does in the UK. They have developed a similar process for recognizing training programs and examinations that they had experienced in the UK. It provide a way for nonuniversity hospitals to have their own training programs and the trainees to have a recognized certification. The problem has been that it is a parallel program in competition with the MMed. The universities have assessed that this certification is inferior to their MMed, and universities are reluctant to lose the revenue stream. The only choice PAACS had was to ask COSECSA to approve their programs. This has been a long, slow, and arduous process. COSECSA has two levels of certification, the Membership and Fellowship. The Membership is an entry level consisting of mainly basic science and basic surgery certification that would be given to a resident completing a level equal to the second year of residency in the

Nov 2016. Christian Journal for Global Health, 3(2): 160-167. 
American system. The Fellowship is a full surgical certification, equivalent to a resident passing the specialty board exam in the US system. The advantage of the COSECSA Fellowship is that it is recognized in all 10 countries covered by COSECSA. One disadvantage of the MMed certification is that it $\mathrm{s}$ conferred by an individual university, so the standard can vary from university to university and from country to country and may not be recognized in all countries. All of the PAACS programs in East and West Africa have been approved for the Membership level by COSECSA, but at present only the Kenyan programs are approved at the Fellowship level. The problem is that at the Membership level, trainees are not recognized by the $\mathrm{MOH}$ as fully qualified surgeons, even if they have completed a five-year training program and are approved by Loma Linda and PAACS. Also some countries require separate approval of the program by the $\mathrm{MOH}$ and Ministry of Education for graduates to be considered specialists.

PAACS has also approached the West African College of Surgeons (WACS) for approval, but this has been even more difficult. So far PAACS has asked them to approve programs in West Africa and have only received approval at the Membership level. Recent negotiations may change this, and approval may be granted at the Fellowship level if certain conditions are met. Another problem is maintaining and attracting expatriate faculty.

\section{Spiritual Training}

One of the initial goals for training residents in mission hospitals was to encourage them to serve in rural mission hospitals and to have them be not only excellent, caring surgeons, but to be equipped to share the good news of salvation and hope with their patients. In the beginning, each program director was to provide a weekly Bible study for the residents and was given recommendations on what to cover, although they were allowed to choose their own study materials. The PAACS
Commission later added a "Dean" of spiritual training as a Commission member and has a standing Spiritual Training Advisory Committee. Reverend Stan Keys has developed a four-part Bible study series, each part to last one year for the program directors and residents. This allows the residents to complete the whole series during their five-year training program. This has helped the programs by having a curriculum and study material available as well as providing a more standardized program. It helps the already busy faculty and residents with the availability of developed printed material.

\section{Needs and Future Directions}

One of the current catch words in global health programs is "sustainability." It is recognized in all high income countries (HICs) that surgical education takes more time and creates more expense than an experienced non-teaching, welltrained surgeon. This is compounded in low and middle income countries (LMICs) where there is a shortage of trainers and an overwhelming number of patients to treat. Many of the patients coming to mission hospitals can only afford minimal payments for medical care. If there is a nearby government facility that is financially subsidized, a mission hospital may not be competitive. They must depend on providing excellent medical and surgical care and a caring attitude to the patients. If the mission hospital is in an isolated rural area, most of the patients may be able to pay only a small amount of the cost, making the hospital dependent on outside funding. Because of this constant financial burden, some mission organizations have chosen to turn their hospitals over to nationals and to get out of the health care "business." This often leads to mission hospitals slowly deteriorating in supplies, facilities, and personnel leading to the eventual closure of the hospital. This raises a question as to whether a mission hospital and, even more relevant to this paper, a surgical training program can be sustainable?

Nov 2016. Christian Journal for Global Health, 3(2): 160-167. 
In some situations, training of national personnel in more efficient hospital administration would help. It is recognized by almost everyone involved that training in hospital administration is a huge unmet need in Sub-Saharan Africa. Addressing this need is beyond the purview of this paper, only to say that global health has concentrated on clinical care and tends to ignore the need in administration, although there are a few organizations starting programs.

In some countries, the $\mathrm{MOH}$ has recognized the important roles mission hospitals play in the delivery of health care. With this in mind, despite their strapped budgets for health care, they do provide some financial support for patient care and medicines. In the area of public health, infectious diseases, such as malaria and HIV, have a high priority by many global non-governmental organizations which help provide care.

One example of the benefits of a surgeon at a hospital is demonstrated by one of the early PAACS graduates who returned to his home country and the mission hospital which provided some support for his training. The 100+ bed hospital had only a medical service, was losing money, and had a declining census, dropping to just 25-30 patients. In less than one year after he returned to provide a surgical service, the hospital was nearly full and the financial balance was positive. Not all graduates have been as successful, but it does demonstrate what can be accomplished. One problem is when a talented individual makes a difference like this clinically, he or she is then promoted to be hospital director, with less time for clinical medicine and, frequently, without adequate training in administrative leadership.

One of the original ideas when PAACS started was that mission hospitals would identify a physician to be trained, pay their stipend, and have the resident return to the hospital to work. Very quickly, it was found that most mission hospitals could not do this. As a consequence, PAACS started paying all the costs to train residents, and the residents agreed to serve in a mission hospital for five years after completion. At present, all of the residents completing the PAACS training have remained in Africa. The majority of residents have joined mission hospitals, but some are working for government hospitals. As PAACS has added more residents, it is now asking for the training hospitals to contribute to the financial support of the residents. Most hospitals have recognized that a training program increases their productivity and attracts patients to their hospital, so most are complying with this request which will help make the program sustainable. PAACS is also heavily dependent on visiting expatriate faculty to supplement the surgical training by the full time faculty as well as experience in surgical subspecialties.

The answer to the question of sustainability is not easy. The economics and budgets of most LMICs will require some outside support. Ideally this support should be as a partnership with mutual goals, not a free handout creating a demeaning dependency.

\section{Employment Opportunities}

When considering sustainability, one must look at paid employment opportunities for graduating residents. So far, the PAACS residents have found positions. Some have been willing to take up opportunities where there have been inadequate facilities to use their training to the fullest potential. Some have had to sacrifice income needed to support their families. Some have taken positions in rural areas while their children had to stay in the city for educational purposes, thus splitting up the family. Some have been in government hospitals where they have been threatened and had to leave, but the majority are working in mission hospitals. A few have been employed at PAACS training hospitals. All of them credit their role models and PAACS for encouraging them to use their training to serve the Lord.

Nov 2016. Christian Journal for Global Health, 3(2): 160-167. 
To be sustainable, training programs need to equip and train the residents to eventually take over the training programs. Many times, teaching is not considered as a career opportunity. As trainers, it is incumbent upon us to be role models and look for those residents who show leadership and teaching skills, and then encourage them to consider training and teaching as a career. It is important that a training program has a goal for nationals to take over running the training program if it is to be sustainable. In many countries, visas, licenses, and approval by $\mathrm{MOH}$ are fragile when governments frequently turnover. When a program is totally dependent on expatriates, it is vulnerable to faculty leaving for health, family, or personal reasons, and the program becoming unsustainable with possible closure. To reduce this possibility, it is important to train residents how to teach and run a program. Programs should try to hire those residents showing an aptitude for teaching. If the program should become self-sustainable in this way, is there a role for expatriates? Yes, there will be a strong role for them, although it may be different than merely filling traditional roles. For many years, there will be a need for expatriates to be available for counselling, mentoring, and advice, but it should be a supportive rather than a directive role. There will also be a need for expatriates to help the national faculty maintain and keep their surgical skills up-todate as they will not have the vast array of continuing education opportunities that those of us in HICs have. Also, they will need help in external, non-biased assessments of their residents and of the program to maintain high quality training standards. So, yes, there will still be a role for expatriate missionaries willing to train and teach.

A recent concern regarding employment for graduating residents is the reluctance of mission hospitals to hire PAACS residents. It is not because they feel they are not well trained, but because they will have to pay them in ways that further strain an already strained budget. Expatriate missionaries have two big advantages. First, they bring their own support, and the hospital does not have to pay them. Second, they will usually bring resources to help the hospital continue to operate. This may be vital to the sustainability of the hospital. A solution to this dilemma is beyond the purview of this paper, but certainly, it is an issue that needs to be addressed by mission and church organizations.

Finally, these training programs rely heavily on expatriate full-time missionaries, but also on short-term surgeons willing to spend time teaching residents and covering for full-time expatriate surgeons temporarily away. Elsewhere in this journal is an article on the mobilization of doctors from HICs willing to serve in LMICs. It is not easy for doctors who wish to serve long-term or shortterm to leave practices, bring families and live in situations that most of us would find difficult. However, we can be thankful that the Lord lays on the hearts of a few to serve Him in this way.

\section{Conclusion}

Surgery has traditionally been an important part of medical mission services, but to make this sustainable, it is important that we include residency training as part of the mission. Starting a surgical residency program will require careful preparation, recruitment of training faculty, and an appropriate educational program. It is important that there be plans for those completing the training to be able to receive credentials that will be recognized by the countries' MOHs. To be a successful, God-honoring program, there must be a strong emphasis on spiritual training and mentoring as well as surgical training. Sustainability will also include the importance of training national physicians to be teachers and to make sure there are employment opportunities available.

\section{References}

1. Kakande I, Mkandawire N, Thompson MIW. A review of surgical capacity and surgical education programmes in the COSECSA region. East Cent Afr J Surg. 2011;16:6-34.

Nov 2016. Christian Journal for Global Health, 3(2): 160-167. 
2. Bode CO, Nwawolo CC, Giwa-Osagie OF. Surgical education at the West African College of Surgeons. World J Surg. 2009;32(10):2162-6. http://dx.doi.org/10.1007/s00268-008-9710-x

3. Price R, Makasa E, Hollands M. World Health Assembly Resolution WHA68.15: Strengthening emergency and essential surgical care and anesthesia as a component of universal health coverage - addressing the public health gaps arising from lack of safe, affordable and accessible surgical and anesthetic services. World J Surg. 2015 Sep;39(9):2115-25. http://dx.doi.org/10.1007/s00268-015-3153-y

4. Mock CN, Donkor P, Gawande A, Jamison DT, Kruk ME, Debas HT. Essential surgery: key messages from Disease Control Priorities, 3rd edition, Lancet. 2015 May; 385(9983):2209-19. http://dx.doi.org/10.1016/S0140-6736(15)6000915. [Epub 2015 Feb 5]

5. Botman M, Meester RJ, Voorhoeve R, Mothes H, Henry JA, Cotton MH, et al. The Amsterdam Declaration on Essential Surgical Care. World J Surg. 2015 June;39:1335-40. http://dx.doi.org/10.1007/s00268-015-3057-x

6. Meara JG, Leather AJM, Hagander L, Alkire BC, Alonso N, Ameh EA, et al. Global Surgery 2030: evidence and solutions for achieving health, welfare, and economic development. Lancet. 2015
Aug 8;386(9993)569-624. http://dx.doi.org/10.1016/S0140-6736(15)60160-X [Epub 2015 Apr 26]

7. Koplan JP, Bond TC, Merson MH, Reddy KS, Rodriguez MH, Sewankambo NK, et al. Towards a common definition of global health. Lancet. 2009 June 6;373(9679):1993-5. http://dx.doi.org/10.1016/S0140-6736(09)60332-9

8. Pollock JD, Love TP, Steffes BC, Thompson DC, Mellinger J, Haisch C. Is it possible to train surgeons for rural Africa? A report of a successful international program. World J Surg 2011 Mar;35(3):493-9. http://dx,doi.org/10.1007/s00268-010-0936-Z

9. World Health Organization. Surgical Care at the District Hospital [Manual]. Malta: Interprint Limited; 2003 [ISBN 924154575 5] Available from: http://www.who.int/surgery/publications/en/SCDH .pdf

10. Lockyer, JM, Hodgson CS, Lee T, Faremo S, Fisher B, Dafoe W, et al. Clinical teaching as part of continuing professional development: Does teaching enhance clinical performance? Med Teach 2016 Aug;38(8):815-22. http://dx.doi.org/10.3109/0142159X.2015.111289 $\underline{5}$

Competing Interests: None declared.

Correspondence: James D Smith, Oregon Health and Science University, Oregon, United States. jamesd.smith@yahoo.com Dan Poenaru, Children's Hospital, Quebec, Canada.dpoenaru@gmail.com David Thompson, Harpur Hospital, Egypt. justthebeginning@hushmail.com J Dwight Phillips, Mayo Clinic, Minnesota, United States. jdwightphillips@gmail.com

Cite this article as: Smith JD, Poenaru D, Thompson D, Phillips JD. Surgical residency training in the mission setting: current status and future directions. Christian Journal for Global Health (Nov 2016), 3(2):160-167.

(C) Smith JD, Poenaru D, Thompson D, Phillips JD This is an open-access article distributed under the terms of the Creative Commons Attribution License, which permits unrestricted use, distribution, and reproduction in any medium, provided the original author and source are properly cited. To view a copy of the license, visit http://creativecommons.org/licenses/by/4.0/

\section{www.cjgh.org}

Nov 2016. Christian Journal for Global Health, 3(2): 160-167. 